\title{
A prática de tutoria online por meio de competências: estudo de caso de uma metodologia aplicada ao curso de Formação de Tutores
}

\author{
Ana Carolina Bertoletti De Marchi - UPF Virtual/UPF - carolina@upf.br \\ Isléia Rossler Streit - UPF Virtual/UPF - istreit@ upf.br \\ Daniela De David Araújo - UPF Virtual/UPF - david@upf.br \\ Marlete Sandra Diedrich - UPF Virtual - marlete@upf.br
}

\begin{abstract}
Resumo: O trabalho de tutoria acompanha o crescimento da Educação a Distância que utiliza ambientes virtuais de aprendizagem para desenvolver propostas de ensino. Desta forma, as definições sobre suas funções e atribuições têm provocado discussões importantes na área. O presente artigo contribui com a apresentação de uma metodologia de curso para a formação de tutores, valendo-se de pressupostos teóricos que sugerem competências mínimas necessárias para a atuação deste profissional. Assim sendo, por meio de um estudo de caso, relata-se a organização do curso de formação para tutores, que, utilizando-se de tal concepção, entrelaçou uma proposta teórica a um ambiente prático de tutoria. Pelo fato da metodologia adotada ser fruto de um projeto piloto, faz-se, ainda, uso de um instrumento próprio de avaliação para a análise do curso ofertado.
\end{abstract}

Palavras-chave: Educação a Distância. Tutoria online.

The practice of online tutoring based on competences: a case study of a methodology applied to a Tutors' Formation Course

\begin{abstract}
.
The online tutoring activities accompany the growth of the Distance Learning projects that use virtual learning environments to develop teaching proposals. Thus, the definitions about the tutor's functions and attributions have been generating important discussions in the area. This article presents a course methodology for tutors' formation, based on theoretical premises that suggest essential competences which are necessary for the action of that professional. Therefore, by means of a case study, the organization of the tutors' formation course is reported. Exploring such concept, the course has linked a theoretical proposal to an environment for the tutors' practice. Considering that the selected methodology is a result of a project in experimental phase, an instrument of evaluation was used for the analysis of the offered course.
\end{abstract}

Keywords: Distance Learning. Online Tutoring. 


\section{Introdução}

A consolidação da Educação a Distância $(\mathrm{EaD})$ por meio da rede mundial de computadores trouxe vários elementos novos para as práticas de ensino em seus diferentes níveis. Dentre eles, a figura do tutor.

Com a acelerada expansão da $\mathrm{EaD}$ na última década, surgem, com maior expressividade, trabalhos e projetos de pesquisas que discutem as funções, as atribuições, as designações e os objetivos do tutor nos cursos online. Desta forma, devemos considerar que a função do tutor, seja a distância ou presencial, passa constantemente por novas definições. Portanto, o conhecimento apresentado neste texto não tem caráter definitivo e trata-se apenas de uma discussão inicial sobre o tema.

Neste contexto, Michael Moore (2007, p. 147) apresenta dois desafios centrais para a função de tutor, a saber:

- o tutor não sabe como os alunos reagem ao que lhes é dirigido, ou seja, a reação quanto ao material que foi preparado (vídeos, textos, imagens, etc.) pode ser diferente para cada indivíduo. Portanto, o desafio reside em conseguir decifrar as reações dos alunos aos diferentes comandos que lhes são dados;

- o conhecimento é conduzido por intermédio de uma tecnologia, ou seja, os tutores precisam descobrir as limitações e o potencial da tecnologia e as melhores técnicas para comunicação por meio dela.

Diante disso, quando falamos em educação a distância devemos considerar algumas capacidades que os profissionais da área precisam ter ou desenvolver, em especial, o tutor. Destaca-se aqui a capacidade para entender as personalidades de seus alunos, mesmo filtradas pelas comunicações transmitidas tecnologicamente (Moore e Kersley, 2007, p. 148).

Pode parecer estranho pensar que a EaD necessite da identificação das emoções dos alunos, porém o apoio motivacional feito da maneira mais próxima possível possibilitará a permanência dos mesmos no curso.

O tutor precisa, antes de qualquer outra ação, entender a importância de orientar o aluno facilitando sua vida de estudante online, construindo as oportunidades de participação, de acesso, de questionamento, bem como, por meio de mecanismos motivacionais, envolvê-lo nas discussões e nas atividades relacionadas ao curso, a ponto de que ele próprio construa as condições gerenciais de sua formação.

Segundo o MEC (2008), o tutor "atua junto aos estudantes sob estrita orientação e supervisão da equipe de docentes, principalmente como mediador pedagógico e facilitador nos processos de ensino-aprendizagem." Portanto, o conceito de tutor envolve, além da delimitação conceitual citada, potencialidades, competências e capacidades vinculadas às múltiplas realidades encontradas em cada atuação. Desta forma, cada profissional terá de desenvolver tais elementos para realizar com proveito sua atividade.

Pensando nisso, este artigo propõe uma metodologia para a prática de tutoria fundamentada em competências. Além da metodologia, o texto irá apresentar sua aplicação em um curso de formação continuada e, por fim, a avaliação com base em um instrumento fundamentado em sistemas de indicadores, adaptado de (Bertolin e De Marchi 2010). 
Diante deste contexto, buscar-se-á: abordar um conjunto de informações básicas sobre a tutoria online; apresentar a metodologia adotada na prática da tutoria online nos cursos de extensão a distância ofertados e discutir alguns resultados obtidos com a avaliação da metodologia.

\section{Atribuições e competências do tutor na aprendizagem online}

O trabalho como tutor online deve suscitar uma pergunta básica inicial: que conhecimentos e competências o tutor deve possuir para desempenhar seu trabalho?

O manual do tutor da COMMONWEALTH (2003) ajuda a elucidar essa discussão, afirmando que as pessoas com experiência de ensino já possuem muitos dos conhecimentos e competências dos tutores da EaD. Os tutores precisam possuir uma gama mais vasta de tais elementos, devido às diferentes abordagens, aos perfis e objetivos dos estudantes virtuais e à utilização de estratégias de comunicação a distância (Manual do tutor COMMONWEALTH, 2003, p. 36).

Desta forma, destacam-se três características que devem estar associadas constantemente às atribuições do tutor: responsabilidade, capacidade e competência. Mercado (2008, p. 98) define o tutor como responsável pela incessante comunicação que desencadeia o processo de ensino-aprendizagem. O tutor é o parceiro constante das esferas envolvidas no processo, ou seja, do professor e, em especial, do aluno, devendo interagir com os dois grupos, tanto com ações motivacionais quanto na resolução de problemas técnicos. Portanto, o andamento do curso a distância depende, em grande escala, da observação e da ação constante do tutor, bem como do levantamento e apontamento das informações de sucesso ou de problemas percebidos aos demais componentes da equipe responsável pelo andamento do curso. Tal atitude exige do tutor autonomia na condução do processo de ensino-aprendizado que está em desenvolvimento.

Belloni (2003, p. 81) nos ajuda a compreender a delimitação da autonomia necessária ao tutor e destaca que este profissional deve ter capacidade para: (i) interagir com os conteúdos e material didático disponibilizado e dinamizado durante o curso; (ii) fazer uso de estratégias de orientação; (iii) realizar as intervenções didáticas com frequência necessária; e (iv) ter disponibilidade para estimular a autonomia e a emancipação do aluno. Cabe destacar que o papel do tutor precisa ser pensado para que não se reproduzam nos atuais ambientes de $\mathrm{EaD}$ concepções tradicionais das figuras do professor. É preciso superar a postura ainda existente, do professor transmissor de conhecimentos.

Juntamente com os elementos de responsabilidade e de capacidade, com a ajuda de Moore (2007, p. 148-149), define-se o termo competência. O autor classifica as funções do tutor em três competências:

(i) as atividades de ensino: significa que este deve conhecer o conteúdo do curso, a ponto de conseguir intervir na discussão, conduzindo-a para um melhor aproveitamento, e também intensificando a interação dos alunos com o conteúdo, mediante suas intervenções;

(ii) as atividades de progresso dos alunos: atuação de acompanhamento da realização das atividades, indicando ao professor o andamento do aluno quanto aos prazos e quanto ao ritmo de envio das tarefas. A competência para estimular 
o progresso dos alunos é um elemento fundamental e de responsabilidade do tutor;

(iii) as atividades de apoio ao aluno: mesmo que a instituição conte com o suporte técnico e administrativo, geralmente questões desta ordem chegam aos tutores e é importante que estes tenham o conhecimento básico a respeito delas para dar o suporte em tempo hábil, sem prejudicar o desempenho dos alunos.

Assim sendo, o tutor deve desenvolver a competência de perceber tudo o que está acontecendo com o aluno em seu processo de ensino-aprendizagem online. É o tutor quem está efetivamente e sistematicamente em contato com o aluno e é, portanto, a fonte de informação mais adequada para com os demais sujeitos da EaD. Além disso, é um dos protagonistas para uma boa experiência de aprendizagem na educação a distância, conforme dois (iv e v) dos cinco itens apontados pelo Manual do Tutor da COMMONWEALTH (2003, p.19) como responsáveis pelos processos de formação, de ensino e de aprendizagem na $\mathrm{EaD}$, a saber:

(i) qualidade, exatidão e abrangência dos materiais de aprendizagem;

(ii) custo, fiabilidade e facilidade de utilização das tecnologias necessárias;

(iii) grau de consistência na abordagem entre os materiais de curso e o processo de avaliação;

(iv) empenho, em termos práticos, da instituição de ensino para com os alunos, como seja a disponibilidade de pessoas para responderem a perguntas;

(v) disponibilidade e prontidão dos tutores para responderem às necessidades dos alunos e para fornecerem uma avaliação clara e atempada do respectivo trabalho.

Desta forma, o tutor deverá entender o processo pedagógico de ensino da educação a distância, que tem o foco no aluno, desenvolvendo a competência para que os níveis de interação com o sujeito aprendiz sejam atingidos satisfatoriamente.

\section{Aspectos metodológicos sobre a prática da tutoria}

A prática da tutoria online cerca-se de vários elementos para atingir bons níveis de qualidade e contribuir para uma boa experiência de aprendizagem. Dentre os elementos, merecem destaque os apresentados na Tabela 1, considerando a atuação do tutor nas três funções de competências apresentadas por Moore (de ensino, de progresso e de apoio).

Tabela 1. Elementos para a prática da tutoria

\begin{tabular}{l|l}
\hline Atividades de Ensino & - participar e direcionar as discussões; \\
& - selecionar os itens mais relevantes de uma discussão e \\
& destacar para o grupo; \\
& - sistematizar temas que foram abordados em \\
& determinados conteúdos; \\
& - fornecer informações que serão orientativas para a \\
& avaliação; \\
& - auxiliar individualmente o cursista com maiores
\end{tabular}




\begin{tabular}{|c|c|}
\hline & $\begin{array}{l}\text { dificuldades; } \\
\text { - fornecer feedback a cada atividade enviada, reforçando } \\
\text { tópicos do conteúdo. }\end{array}$ \\
\hline Atividades de Progresso & $\begin{array}{l}\text { - orientar os alunos sobre as etapas do curso; } \\
\text { - motivar o aluno e o grupo; } \\
\text { - enviar mensagens de alerta para o cumprimento dos } \\
\text { prazos; } \\
\text { - estabelecer uma rotina de trabalho, junto ao aluno; } \\
\text { - publicar sistematicamente o relatório de } \\
\text { acompanhamento. }\end{array}$ \\
\hline Atividades de Apoio & $\begin{array}{l}\text { - identificar erros nas mídias que compõem o curso, } \\
\text { durante seu desenvolvimento; } \\
\text { - ajudar nos casos de dificuldades de acesso ao curso e } \\
\text { aos recursos disponíveis no ambiente virtual; } \\
\text { - auxiliar, quando solicitado, sobre problemas vinculados } \\
\text { ao conhecimento básico de informática; } \\
\text { - orientar o aluno quanto à organização dos arquivos (de } \\
\text { conteúdo e atividades enviadas) no computador pessoal, } \\
\text { para fins de backup. }\end{array}$ \\
\hline
\end{tabular}

Diante dos elementos citados, é possível perceber que o tutor desempenha o papel daquele que "desperta" os alunos para a rotina de estudo peculiar que acompanha a educação a distância. Conforme diz Gonzales (2005, p. 47), o tutor com uma radiografia didático-avaliativa do aluno terá um perfil minuciosamente detalhado dele, o que lhes permitirá ações de apoio, reforço e orientações adequadas e oportunas.

Além disso, o tutor também deve ficar atento às possíveis causas de evasão, comuns ao processo de ensino a distância e que devem ser minimizadas. Pensando nisso, Gonzalez (2005, pág. 46) aponta quatro causas consideradas como principais, a saber:

(i) conteúdos confusos, com linguagem inadequada ao nível do aluno (muito pobre ou extremamente sofisticada);

(ii) interface com poucos recursos ou extremamente complexa;

(iii) excesso de atividades solicitadas;

(iv)falta de acompanhamento sistemático do tutor.

O feedback, fundamental na prática da $\mathrm{EaD}$, integra o processo de aprendizado a distância como um dos elementos instrucionais presentes nos cursos. Filatro (2008) afirma que se trata de uma forma de retroalimentar a equipe durante o desenvolvimento e a implementação do aprendizado. Para melhor compreensão, podemos utilizar o significado clássico do termo que visa ao retorno de uma informação ao aluno durante 
ou após o desenvolvimento de uma atividade. Tal definição deixa implícito o seu fluxo contínuo. Os feedbacks podem ser personalizados e contextualizados, oriundos diretamente do tutor ou programados pelo sistema gerenciador da aprendizagem.

De modo a definir características comuns para a tutoria em nossa Instituição, elaboramos alguns indicativos para conduzir o trabalho do tutor quanto às características das mensagens e quanto aos modelos de relatórios que devem ser emitidos ao professor da disciplina e à equipe que acompanha o curso. A Tabela 2 ilustra as características das mensagens enviadas aos alunos pelo ambiente de aprendizagem Moodle, conforme a ferramenta utilizada.

Tabela 2. Características das mensagens

\begin{tabular}{|c|c|c|}
\hline Ferramenta & Função da mensagem & Direcionamento \\
\hline Correio & $\begin{array}{l}\text { - motivar os alunos; } \\
\text { - esclarecer sobre as atividades; } \\
\text { - informar prazos e datas. }\end{array}$ & $\begin{array}{l}\text { De caráter individual e } \\
\text { coletivo. }\end{array}$ \\
\hline Fórum & $\begin{array}{l}\text { - nortear a discussão (propondo o } \\
\text { debate); } \\
\text { - contribuir com a temática } \\
\text { abordada; } \\
\text { - buscar o foco da discussão. }\end{array}$ & De caráter coletivo. \\
\hline Diário & $\begin{array}{l}\text { - motivar o aluno, mostrando que } \\
\text { seus registros pessoais estão sendo } \\
\text { acompanhados. }\end{array}$ & De caráter individual. \\
\hline $\begin{array}{l}\text { Envio } \\
\text { Arquivos }\end{array}$ & $\begin{array}{l}\text { - detalhar aspectos positivos e } \\
\text { negativos do trabalho enviado, } \\
\text { visando ao aperfeiçoamento da } \\
\text { atividade; } \\
\text { - promover a sistematização do } \\
\text { aluno. }\end{array}$ & De caráter individual. \\
\hline Bate-papo & $\begin{array}{l}\text { - motivar os alunos; } \\
\text { - realizar uma aproximação afetiva; } \\
\text { - esclarecer dúvidas sobre atividades; } \\
\text { - introduzir a temática abordada no } \\
\text { curso; } \\
\text { - servir como um porto seguro ao } \\
\text { aluno, ponto de encontro. }\end{array}$ & De caráter coletivo. \\
\hline
\end{tabular}


Outra responsabilidade atrelada à função do tutor é o preenchimento e o envio de relatórios de acompanhamento, que devem conter informações relevantes da prática tutorial. A Tabela 3 ilustra os tipos de relatórios de acordo com o sujeito destinatário.

Tabela 3. Tipos de relatório a serem preenchidos pelo tutor

\begin{tabular}{|c|c|c|}
\hline Sujeito destinatário & Relatório & Objetivos \\
\hline Para o professor & $\begin{array}{l}\text { - de acesso ao Moodle; } \\
\text { - de realização das } \\
\text { atividades no prazo } \\
\text { solicitado. }\end{array}$ & $\begin{array}{l}\text { - informar dados do } \\
\text { acesso e a realização } \\
\text { das atividades; } \\
\text { - encaminhar } \\
\text { orientações sobre o } \\
\text { acesso ao Moodle; } \\
\text { - esclarecer sobre o } \\
\text { andamento das } \\
\text { atividades da } \\
\text { disciplina } \\
\text { (operacionais ou de } \\
\text { conteúdo). }\end{array}$ \\
\hline Para o aluno & - das atividades realizadas. & $\begin{array}{l}\text { - orientar quanto às } \\
\text { atividades já } \\
\text { concluídas e quais } \\
\text { ainda encontram-se } \\
\text { com pendência; } \\
\text { - reforçar o prazo para } \\
\text { cumprimento das } \\
\text { atividades; } \\
\text { - esclarecer sobre o } \\
\text { funcionamento da } \\
\text { disciplina, das } \\
\text { atividades, dos prazos } \\
\text { a cumprir. }\end{array}$ \\
\hline $\begin{array}{l}\text { Para } \quad \text { a } \\
\text { técnica/secretaria/coordenação } \\
\text { do curso }\end{array}$ & $\begin{array}{l}\text { - de acesso dos alunos e } \\
\text { professores ao Moodle; } \\
\text { - de realização das } \\
\text { atividades no prazo. }\end{array}$ & $\begin{array}{l}\text { - avisar sobre o não } \\
\text { funcionamento de } \\
\text { mídias, arquivos etc; } \\
\text { - avisar quanto aos } \\
\text { problemas de acesso } \\
\text { enfrentados pelos } \\
\text { alunos; } \\
\text { - encaminhar e } \\
\text { esclarecer diferentes } \\
\text { situações técnicas que }\end{array}$ \\
\hline
\end{tabular}


Ressalta-se, por fim, que a prática da tutoria desenvolvida pela equipe de tutores de uma instituição está vinculada à concepção didático-pedagógica adotada pelo grupo. Tal posição de trabalho significa que a ação coletiva e o entrosamento entre os tutores vinculados a um projeto de curso em execução são fundamentais para o sucesso da proposta.

\section{Avaliação da prática da tutoria adotada}

A prática da tutoria online adotada culminou na concepção de um curso de formação para este profissional da EaD. Tal curso seguiu os pressupostos teóricos e as opções metodológicas condizentes com as discussões atuais do tema.

O curso de Formação de Tutores, ofertado por nossa Instituição, possui como objetivos: (i) capacitar tutores para atuar em cursos a distância; (ii) oportunizar aos participantes o conhecimento de ferramentas tecnológicas empregadas em EaD; (iii) atualizar os cursistas no que diz respeito às discussões acerca de aspectos legais e práticos relacionados à inserção das tecnologias da informação e da comunicação aplicadas ao ensino; e (iv) conhecer e construir ações práticas da tutoria.

Ao longo do curso são desenvolvidas atividades individuais e em grupo (estudos de caso, questões discursivas, fóruns de discussão e chats, além de atividades práticas) que permitem aos tutores construir os referenciais básicos de educação a distância e as características da tutoria, quanto a situações do contexto profissional prático do ensino online.

Ao todo foram 40 horas de atividades, distribuídas em seis semanas, tendo o ambiente virtual de aprendizagem Moodle como principal recurso tecnológico utilizado. $\mathrm{O}$ acesso ao curso está totalmente disponível no período de sua vigência, permitindo uma maior flexibilidade de horário de estudos. Foram disponibilizados materiais em formato doc, pdf, HTML, ppt, flash e vídeos.

Como principal estratégia de experimentação da prática tutorial por parte dos alunos, adotaramse cursos virtuais com atividades e alunos fictícios, simulando uma rotina de trabalho. Cada aluno ficou responsável por um curso e, durante o período em que estava realizando a tutoria dos alunos fictícios, foi observado e avaliado, recebendo feedback sistematicamente.

Para a avaliação da prática da tutoria, adaptou-se um instrumento fundamentado nos sistemas de indicadores proposto por Bertolin e De Marchi (2010). Ao todo, foram 15 cursistas respondentes e um total de 10 questões. A cada questão, o respondente deveria selecionar uma resposta em uma escala de 1 a 5 , sendo 5 o maior conceito.

Os resultados obtidos comprovaram a aprovação da metodologia adotada por meio de competências. As práticas de tutoria relacionadas às três competências do tutor (atividades de ensino; de progresso e de apoio) foram avaliadas com média 4,8, demonstrando conhecimento do conteúdo a ponto de intervir na discussão; acompanhamento na realização das tarefas, com a atualização constante do relatório de notas e comentários; e conhecimento básico de questões de suporte técnico e administrativo, atendendo as diferentes solicitações quanto à dificuldade de acesso e postagem de tarefas, por exemplo. A questão com maior média $(4,9)$ foi "As habilidades 
e competências dos tutores para o desenvolvimento do curso podem ser avaliadas como?".

Outro forte indício de que a prática da tutoria adotada foi bem-sucedida é o percentual de alunos aprovados, cerca de $90 \%$. O índice de evasão ficou em 10\% (dois alunos), dos quais um relatou a impossibilidade de continuar, tendo em vista tarefas assumidas após o começo do curso.

Ao final de curso, os alunos emitiram depoimentos espontâneos sobre a prática adotada. Tais depoimentos foram classificados conforme as competências exigidas pelo tutor, a saber:

a) Atividades de apoio:

"Talvez minha dificuldade tenha ocorrido por nunca ter trabalhado com essas ferramentas e me senti insegura em usá-las, mas sempre encontrei respostas quando as busquei junto aos tutores." (P.F.M.)

b) Atividades de ensino:

"O trabalho de vocês como tutoras foi ótimo, tudo que lemos na teoria vocês fizeram na prática: envolvimento com os alunos e discussões, atividades claras, responderam nossas dúvidas,... Com vocês sanei as principais dúvidas sobre EaD e agora tenho certeza que quero continuar fazendo cursos nessas áreas." (L.I.G.)

c) Atividades de progresso:

"Quero agradecer a vocês pela atenção, orientações, a forma como conduziram as atividades e principalmente por estarem sempre disponíveis.” (S.M.G.)

“ Gostaria, em primeiro lugar, de parabenizá-las pela eficiente tutoria realizada. $O$ apoio na realização das atividades, bem como o retorno sobre o desempenho nestas, sempre foram prestados com rapidez e qualidade. Além disso, a atenção e a disponibilidade no atendimento também merecem ser elogiados." (C.K.)

A partir da análise desses dados, pode-se afirmar que a avaliação resultante aponta para caminhos bastante produtivos quanto à escolha e adoção da metodologia para a prática de tutoria online. O aluno virtual em foco neste trabalho dá sinais de que, a partir da metodologia empregada, ultrapassou seus obstáculos iniciais e, a cada nova etapa no curso, sentia-se mais seguro em sua ação.

\section{Considerações Finais}

Suprir a ausência física do professor transfere ao tutor a responsabilidade de orientar o aluno virtual, construindo oportunidades de participação, de acesso, de questionamento, envolvendo-o nas discussões e exigindo a adoção de mecanismos motivacionais.

As atribuições atreladas ao tutor vão desde questões de ensino até aspectos gerenciais do curso. Neste artigo foi proposta uma metodologia de prática da tutoria tendo em vista as funções do tutor relacionas às três competências exigidas nas: (i) atividades de ensino; (ii) atividades de progresso e (iii) atividades de apoio. 
A aplicação da metodologia em um curso de formação de tutores apresentou indícios de que a proposta foi bem sucedida. Tal constatação é decorrente, principalmente, dos bons resultados obtidos pelos alunos na realização das atividades propostas. Portanto, torna-se possível afirmar que a metodologia empregada no curso de formação de tutores destacou-se, em especial, por atrelar teoria e prática, o que garantiu aos alunos a experiência concreta da tutoria sob o acompanhamento da equipe responsável. Esta situação permitiu aos alunos assumir responsabilidades cada vez mais complexas e tomar decisões importantes na condução do processo. Entretanto, não o fizeram por conta própria ou sem reflexão acerca das causas e consequências que os estavam movendo. A ação de tutoria foi embasada em princípios e encaminhamentos recebidos durante todo o curso, o que comprova a necessidade de o tutor desenvolver habilidades didáticas e avaliativas no intuito de melhor atuar na tomada de decisões, permitindo-lhe uma intervenção mais qualificada.

Por fim, consideramos a prática de tutoria online por meio de competências uma metodologia adequada e capaz de render bons resultados na construção do conhecimento, a qual se dá pela interação e como resultado da ação coletiva.

\section{Referências Bibliográficas}

Belloni, M. L. Educação a distância. Campinas, SP: Autores Associados, 2003.

Bertolin, Júlio C. G. ; Marchi, Ana Carolina B. De . Instrumentos para avaliar disciplinas da modalidade semipresencial: uma proposta baseada em sistemas de indicadores. Avaliação (UNICAMP), v. 15, p. 1-10, 2010.

COMMONWEALTH of Learning (col): Tutoria no EaD: Um manual para tutores. Canadá. 2003. <Diposnível em: http://www.abed.org.br/col/tutorial.pdf> Acesso: 12 maio 2011.

Filatro, Andrea. Design instructional na prática. São Paulo: Pearson Education do Brasil. 2008.

Gonzalez, M. Fundamentos da Tutoria em Educação a Distância. São Paulo: Editora Avercamp, 2005.

MINISTÉRIO DA EDUCAÇÃO. Instrumento de avaliação de cursos de graduação. Brasília, 2008. <Disponível em http://www.ufrb.edu.br/cpa/index.php/.../66instrumento...cursos/download> Acesso: 5 mar de 2011.

Mercado, Luis Paulo Leopoldo (org.). Práticas de Formação de Professores na Educação a Distância. Maceió: EDUFAL, 2008.

Moore, Michael e Kearsley, Greg. Educação a Distância - uma visão integrada. São Paulo: Thomson Learning. 2007. 